\title{
THE R FILES: APPLYING RELEVANCE MODEL TO CONSPIRACY THEORY FALLACIES
}

\author{
DAVID CASACUBERTA \\ Autonomous University of Barcelona \\ CAROlina Figueras \\ University of Barcelona \\ ROSER MARTíneZ \\ University Pompeu Fabra of Barcelona
}

\begin{abstract}
The general aim of this article is to test how the relevance model can be of use to model argumentation. More specifically, to check if the theory developed by Sperber \& Wilson (1986) is able to explain some specific fallacies, the so called "conspiracy theory fallacy".

This paper contains: a short introduction both to fallacies and to relevance theory; a summary of two real conspiracy theories taken from the book "The 60 greatest conspiracies of all times", and a detailed analysis of these two conspiracies by means of the relevance model.
\end{abstract}

\section{INTRODUCTION}

Despite its power to explain several pragmatic effects, the relevance model developed by Sperber \& Wilson has very seldom been used to explain pragmatic effects in argumentations. Our goal in this paper is to show how relevance can be a very useful tool to explain such effects, taking as an example a complex fallacy commonly known as "conspiracy theory". We aim to show how reasons for rejecting such pragmatic arguments can be explained by means of Sperber \& Wilson modelling. 
First of all, we would like to deal briefly with the notion of conspiracy: Talking about "conspiracy" probably means for most speakers to activate knowledge about specific events, usually politically ones. These events tend to be controversial and complex, basically due to the variety and number of elements and forces involved. They are, to a certain extent, part of the shared knowledge which belongs to our ordinary life in society.

Following the definition that appears in the Diccionario de la Real Academia (1992), "conspiracy" evokes the idea of certain people joining their efforts against someone superior in order to harm them and, in a figurative sense, "the gathering of various things towards the same end". According to Webster's Encyclopedic Unabridged Dictionary of the English Language (1994) it is "an evil, unlawful, treacherous, or surreptitious plan formulated in secret by two or more persons; a plot." We could say then that conspiracies - made into public events and filtered by media- are a discursive fact which has an argumentative aspect. After all, conspiracies aim at convincing -in this case, the public opinion-, but they also have a clear intention of destroying the public image of a person or corporation. This means all kinds of arguments are used to reach this end. One of these, of course, is the "argumentative fallacy".

To convince someone it is necessary to gather a set of arguments (or premises) which in a logical or truthful way leads the receiver towards the conclusion (thesis) we want to make. To do so, sometimes we are "obliged" to use certain persuasive strategies which are not really legitimate, that is, which are deceptive.

In this paper, we will focus upon conspiracy theories, and, specifically upon two kinds of fallacies, which have already been described by several scholars, and which are almost a basic constant in every conspiracy theory: the "ad hominem" fallacy, and the "patchwork quilt" fallacy. We will use relevance theory as our theoretical framework. Two of its main concepts, namely "context" and "contextual effect", will be of great help to explain such complex verbal argumentations. The empirical material we will use are two texts taken from Vankin \& Whalen (1995). The two texts mentioned are also freely available in Internet at htpp: www.conspire.com/chaps.html

The first text ("The Jonestown Massacre. CIA Mind Control Run Amok"), is built around "data". The authors try to convince us by using so-called "facts" (dates, family names, quotations, and so on). What the argumentation aims to do is discredit the main character, the reverend Jim Jones, in front of the almighty but always criticised CIA, using arguments against him, from his infancy until his suicide.

The second text ("Those Christ Kids") is an excellent example of argumentative construction which is based on the intrinsic power of the convictions which "ancient mysteries" generates in some people: The power of what can not be proved. The text 
aims to "prove" that Jesus Christ did not die in the cross after all, and offers as evidence the fact that his direct descendants are alive and prospering.

\section{WHAT IS A FALLACY?}

Before taking up these texts in detail, we would like to put forward some ideas about fallacies. First of all, the traditional classification of fallacies is of little use to help people detect fallacious arguments, such as are sought in critical thinking, for example. So, let us pay some attention to logical fallacies. These are the fallacies which intentionally or unconsciously break a first order logic rule. Thus, if someone states (1) and (2):

(1) If Kennedy was killed in a conspiracy, then there should have been some inconsistencies in his autopsy;

(2) There were some inconsistencies in Kennedy's autopsy;

then they may easily conclude (3):

(3) Kennedy was killed in a conspiracy.

This is a common logical fallacy, known as assertion of the consequent, and it is a fallacy because it breaks "modus ponens" and "modus tollens" rules, which are the only rules to obtain conclusions from a if ... then ... statement. Unfortunately, this kind of analysis of fallacies are of very little use, because: (a) they are uncommon, and (b) the receiver can easily spot this kind of fallacy without much formal training.

We have another kind of fallacy, the non-formal fallacy, which has been studied by rhetoricians at least since Aristotle. They are almost common lore; the most famous being "ad hominem", "ad baculum", "post hoc ergo proper hoc", among others.

This analysis of fallacies does not rest on logical properties, but on general facts about human cognitive habits. However, it has a built-in problem: the description of why the fallacy remains vague as if to be of little real use except in test cases. In fact, here the fallacy is so obvious that theoretical analysis makes no sense. For example, if I say that,

(4) According to Einstein space and time are closely interconnected, but he was very ugly, so his opinions have to be false.

This is clearly an "ad hominem" argument, but it is so simple and obvious that no one needs to get hold of a fallacy listing to see why it shows an incorrect argument. Moreover, this categorisation of fallacies is of little use because not every appeal to authority or critique of the author of an argument is fallacious. According to the classical view, using an authority's opinion to defend a thesis is a kind of fallacy. As a matter of 
fact, it is classified as a case of "ad verecundiam" ("towards reverence"). However, there are plenty of cases when this "fallacy" is correctly used. For example:

(5) According to the experts in the nuclear plant, the radioactive escape is dangerous and the population should leave the surroundings as soon as possible.

It would be quite silly to stay at home, near the nuclear plant, thinking that "well, this is an "ad verecundiam" fallacy: I won't move until someone produces a good argument". We trust experts continuously in our daily life, and it would be foolish not to do so, specially in matters where the "real argument" is too technical and complex to follow.

Another, much more successful way of arguing comes from the book Understanding Scientific Reasoning (1992), by Ronald Giere, where some arguments are viewed from the epistemological point of view, that is, as ways to establish the truth of a hypothesis. Fallacies are ways of arguing in favour of a hypothesis which does not really follow the scientific method or some specific connections in human reasoning.

We would like to pay special attention to a specific fallacy analyzed by Giere: the "patchwork quilt" fallacy. In this fallacy, the person arguing presents unconnected facts, taken from several fields and presents a rather implausible hypothesis according to which, if correct, all those unconnected facts would be explained. Of course, the main point is that there is no real need to explain the unconnected facts, so the evidence does not help to take the hypothesis seriously.

Von Daniken's speculations about extraterrestrial beings visiting the Earth in ancient times is a perfect example of that kind of fallacy: several facts which strike us as enigmatic (pyramids in Egypt and South America, strange prehistoric paintings depicting humanoid figures, and so on), but clearly unconnected, are offered as evidence to support a not-so-sound hypothesis: all these constructions were directly constructed or supervised by intelligent beings from other planets.

"Ad hominem" and "patchwork quilt" fallacies are commonplace in conspiracy theory arguments. We believe that both fallacies can be explained and analysed using the theoretical framework proposed by relevance theory, because they entail the incorrect use of context and contextual effects. However, before taking this path in the paper, we would like to mention some basic notions concerning the relevance model.

\section{RELEVANCE THEORY: MAIN NOTIONS}

\subsection{The notion of relevance}

Sperber \& Wilson (1986) postulate that human cognition tends to be oriented to the maximisation of relevance. The aim of human beings is to maximise their cognitive 
resources in every communicative situation. Because of the fact that information processing consumes cognitive effort, Sperber \& Wilson assume that speakers only process the information which can be considered as relevant. Relevance is a cognitive principle which guides the production, transmission and interpretation of information.

Since relevance is a cognitive principle, the speaker has to maximise the relevance of his/her utterance. On the other hand, the hearer assumes that the speaker tries to communicate something which is worth processing. Therefore, every ostensive communicative act communicates the presumption of its optimal relevance.

Relevance is a comparative concept, so it must be defined in comparative degree terms. Under identical conditions, the utterance which has greater contextual effects with minimal cognitive effort is the most relevant one. And vice versa.

\subsection{The notion of context}

From the standpoint of relevance theory, context can be seen as a set of premises (that is, assumptions, mental representations) which are used in the deductive process of interpretation. The context behaves as a dynamic mental representation in which memory (both short term and long term), information, knowledge and the inferential capacities of the individual are used. Context selection depends on relevance considerations (Sperber \& Wilson 1986).

Any individual has a great amount of information available, but only a small part of it is useful to process new information. When a deductive process starts, the speaker has in memory an initial set of assumptions to begin the interpretation process. Actually, the initial context includes information recently processed; in discourse, the initial context includes information used in the interpretation of the former utterance, plus the information obtained from it.

For example, our first text "The Jonestown Massacre CIA Mind Control Run Amok?" (from now on, "JM text") uses lots of word-triggers which are able to activate huge blocks of encyclopaedic information. This information is used throughout the article to make the argument more plausible. The title speaks for itself: expressions like "Jonestown Massacre, "CIA", "Mind Control" direct us to an initial context formed by assumptions such as:

"The CIA always hide evidence".

"The CIA has made lots of experiments about mental control".

"People who committed suicide in Jonestown were under some kind of mental control".

These assumptions help the reader to accept the conspiracy more easily. 
In contrast, the second text "Those Christ Kids. Descendants of Jesus? Or Scam Artistes Extraordinary?" (from now on, "CK text") has a very complex plot in which almost all the context has to be explained. If we take into consideration the title again, we see how expressions like "Christ kids" do not lead us to any significant block of information (as a matter of fact, the common belief states that Jesus never had kids).

\subsection{Strength of assumptions}

According to Sperber \& Wilson (1986) assumptions are mental representation of the real world which every speaker accepts as truthful. However, not every factitive assumptions are true to the same degree. Some are more truthful than others. In fact, there is a hierarchy among assumptions. It can be observed that:

a) When there is a contradiction between two assumptions, the speakers accepts the more plausible one.

b) When a speaker has to choose between two possibilities, s/he tends to select the one which is more likely.

Going back again to our two texts, in both of them the reader has to make a choice between two assumptions. Both present a "yes-no" dilemma: "Did the CIA orchestrate the Jonestown Massacre?"; "Did Christ move to France and have descendants there?". To answer "yes" to the first one is more likely than to do the same with the second one, because the idea of the CIA conducting a massacre to hide proof of mischief is a lot more plausible than the idea of Jesus Christ moving to France and leading a family life.

This intuition can be borne out by the idea in Sperber \& Wilson (1986) that the strength of an assumption depends on how knowledge has been obtained. If the source of the assumption is direct experience, its strength is greater. Then, we have those assumptions which have been communicated by other people. Depending on the "authority" of the transmitter, the hearer will grant more or less credibility to the assumption.

\subsection{Types of contextual effect}

According to Sperber \& Wilson (1986), the process of interpreting utterances implies the achievement of contextual effects. Information is relevant to someone if it has a contextual effect in an accessible context. New information is processed automatically by the deductive system in relation to the assumptions stored in the mind. In the relevance program we have three different contextual effects: 
a) contextual implications (that is, derivation of new assumptions from deductions made through the interaction between new and old information);

b) contextual strengthening (the new information reinforces a previous assumption) and

c) contextual contradictions (the new information weakens or contradicts a previous assumption).

In the case of a contextual reinforcement, the inferential mechanism will raise the strength of the assumption under consideration. When a contextual contradiction is made, the situation is solved giving more credibility to the stronger assumption.

Returning to our texts, the JM text exploits contextual strengthening ("The CIA is always promoting conspiracies") to obtain the contextual implication of the CIA being the final executors of the Jonestown Massacre. However, the CK text needs to eliminate an assumption ("Christ did not have any descendants") before the reader is able to believe the plot. The elimination is achieved by means of contextual contradictions.

In Sperber \& Wilson (1995) a difference is made between cognitive and contextual effects. The authors claim that a stimulus is relevant if its processing produces cognitive gains. Relevance in a context is a formal property. A context does not perform any cognitive function, and therefore cannot obtain true representations or lose false representations. On the contrary, relevance for an individual implies changes in individual beliefs. An individual has the possibility of gaining or losing interest in whether her/his beliefs are true or false.

According to Sperber \& Wilson (1995) the contextual effects are cognitive effects for an individual. Cognitive effects are contextual effects which take place in the cognitive system of the individual. Cognitive effects produce changes in the beliefs of an individual.

\section{RELEVANCE AND FALLACIES: APPLICATION}

As stated above, our approach aims to explain why some fallacies related to conspiracies have a psychological plausibility that could be analysed in terms of relevance theory.

The JM text aims to show the reader that Jim Jones, the religious leader of the People's Temple, was a CIA agent, and that the CIA was ultimately responsible for 911 deaths, ordered to cover up mental control experiments.

The text presents several fallacies. However, we would like to analyse a specific type which is used throughout the article, a variation of the "ad hominem" fallacy. As a 
matter of fact, the main argument of the JM text is built on a collection of "ad hominem" arguments and "patchwork quilts".

Here is a short list of the "ad hominem" arguments used against Jones in the text, grouped under different headings:

\section{Biography:}

Son of a KKK man and a Cherokee Indian.

Parapsychological experiences during his youth (UFOs, faith healing, visions of nuclear holocaust, fainting spells).

Anti-communist.

Ex-Marine, gigolo and CIA agent (unconfirmed rumours).

Jones declared himself to be the reincarnation of both Jesus and Lenin.

Personal relationships:

Jones' deputies did meet frequently with Soviet officials.

Jones' Lieutenant's brother in law was a CIA-backed UNITA member.

Jones' Lieutenant's father declared that his son was a robot.

\section{Situational facts:}

Dwyer, one of the ambassadors that visited Jonestown, was a CIA agent.

A Berkeley professor published a report about the CIA running mind control experiments, confined in religious cults.

Despite being an anti-racist sect, leaders were always white, and some people believed that it was a "plan like the Germans" to exterminate blacks".

Some of this information (Jones and his lieutenant being CIA covert agents, the CIA running mind control experiments among religious sects) is used to directly prove that Jonestown was a CIA mind control experiment. However, the rest of the information is only used to show how Jones was a very extravagant man. This extravagance leads the reader to believe that Jones was really a member of the CIA. The argument runs more or less like this:

(6) Jones was so eccentric that his biography can not be true. Then his real life is a secret. Therefore, he was a CIA agent.

What is wrong with these arguments? The arguments based on direct information are too problematic, because we only use rumours to state that Jones was a CIA agent. 
Therefore, we need another way to prove that Jones was a CIA agent. This is why (6) is so important for the sake of the argument.

Why would some people take (6) as plausible? According to the relevance model, we tend to consider as more relevant a contextual effect that needs a minimal cognitive effort. The authors present contradictory information which is very difficult to include in a single explanation. In order to join together this information to obtain positive cognitive effects, the authors use a keyword (the CIA) that triggers a frame which helps the reader to construct a relevant context to process the information. Because of the fact that frames offer stereotypical knowledge about the world, any new information can be interpreted with a minimal cost of processing.

Moreover, our frame about CIA contains lots of information about secrecy, conspiracy, cover-ups, blackmailing, killings, and so on. Therefore, the reader who receives new information confirming these assumptions will probably reinforce them, and will accept the conclusion easily.

Let us suppose that the authors use the UNESCO frame instead of the CIA frame. That is, the main argument is the same, but all the references to CIA have been replaced by UNESCO references. Will these arguments work? Probably not. The reason is that our frame about UNESCO does not include anything about conspiracies and related deeds. Then the reader who receives the new information will take it as contradictory with the things s/he knows, and will consider the conclusion as implausible.

Note that the real argument and our invented one about UNESCO are the same from a formal point of view. We can present logical evidence to state that they are both fallacies, but we can not explain why the first one is a lot more plausible than the second one. However, we can understand this effect by means of the relevance model.

Let us move to the CK text. This text "exposes" a very complex conspiracy which covers several centuries and countries, implicates hundreds of sects, organizations and famous people. The main line of the plot is that Jesus Christ did not die on the cross. He moved to France, had descendants, and the search for the Holy Grail was a code-name to keep the bloodline of Jesus alive, so eventually, one of his sons would be able to rule the world.

This time, the main argument is based on the idea of mystery. In a classical "patchwork quilt" style, several unconnected facts are presented to give support to the conspiracy mentioned in the previous paragraph. Most of these facts have in common an appeal to occult arts and secret societies.

As we did for the JM text, we now classify these facts can be classified under the following headings: 


\section{Mysterious facts}

A Visigothic pillar with a series of ciphers and codes which can not be deciphered with modern computers.

A Visigothic treasure hidden in a place of pilgrimage (Rennes-le-Chateau) that the Nazis want to find out.

The real nature of the treasure is some kind of information related to the Holy Grail which is used to blackmail the church.

\section{Secret societies}

The Priory of Zion is a secret society which appears in the ciphers.

There are connections between the Priory of Zion and the Knights Templar.

The Knights Templar was an order of warrior monks which had the secret mission of preserving the Holy Grail.

The Knights Templar's quarters were built on the ruins of the Temple of Solomon.

\section{Related historical figures}

Emma Calve, a famous opera diva and a high priestess of the Parisian esoteric underground, frequently visited Rennes-le-Chateau.

Leonardo da Vinci, Sir Isaac Newton, Charles Raddclyffe, Victor Hugo and Jean Cocteau were probable members of the Priory of Zion.

As we said above, the main argument is a "patchwork quilt". There are several mysterious facts that need an explanation. The only reasonable one is that there has been a vast conspiracy to keep the bloodline of Jesus Christ alive.

Of course this conspiracy is less plausible than the one developed in the JM text. To accept the new information about a vast conspiracy first of all we need to refute basic beliefs that almost everybody has. For example:

(7) Jesus Christ did die on the cross.

(8) Jesus Christ did not have any children.

(9) Conspiracies never last for centuries.

Following relevance criteria we could say that the main assumption which can be obtained from the argument (namely, that there has been a vast conspiracy to keep Jesus' bloodline alive so one of his descendants will rule the world some day) is irrelevant for all the people which firmly believe (7), (8) and (9).

We can note the differences between the two conspiracies: the first one offers a relevant assumption which some people could believe, or at least accept as possible. 
However, in the second one, despite having relevant statements which some readers could accept (for example, that there are Visigothic ciphers impossible to interpret nowadays), the main assumption is irrelevant, because it would not produce any positive cognitive effect in the majority of the readers (see Sperber \& Wilson 1995).

\section{ConClusions}

Despite the fact that they are all fallacies, some conspiracies are more plausible than others. This cannot be explained by means of logical analysis, but it can be shown by using relevance theory as a frame for interpretation.

Some conspiracies are plausible because they refer to a stereotypical context which facilitates the processing of new information. This probably happens because we reinforce pre-existing assumptions.

Some conspiracies, despite having relevant statements in the main argument, can lead to assumptions that are irrelevant.

These and similar phenomena are possible because of the fact that in verbal comprehension the speakers use a kind of non-demonstration inference, based in heuristic reasoning difficult to falsify.

\section{BIBLIOGRAPHY}

Giere, R. 1992. Understanding Scientific Reasoning. New York: Holt Rinehart \& Winston.

Real Academia Española. 1992. Diccionario de la lengua española. Madrid: EspasaCalpe.

Sperber, D. \& D. Wilson. 1986. Relevance. Communication and Cognition. Oxford: Basil Blackwell.

Sperber, D. \& D. Wilson. $1995^{2}$. Relevance. Communication and Cognition. Oxford: Basil Blackwell.

Vankin, J. \& J. Whalen. 1995. 60 Greatest Conspiracies of All Time. New York: Citadel Press Boobs.

Webster's Encyclopedic Unabridged Dictionary of the English Language. 1994. New York: Random House. 